\title{
Identification of a major quantitative trait locus, qGER4.2, conferring resistance to Gibberella ear rot in maize using a Chinese recombination inbred line population
}

\section{Guangfei Zhou}

Nanjing Agricultural University

Shunfa Li

Nanjing Agricultural University

Liang Ma

Nanjing Agricultural University

Fang Wang

Nanjing Agricultural University

Yali Sun

Nanjing Agricultural University

Xinsen Ruan

Nanjing Agricultural University

Yu Cao

Nanjing Agricultural University

Qing Wang

Nanjing Agricultural University

Xiquan Gao ( $\sim$ xgao@njau.edu.cn )

\section{Research article}

Keywords: Maize (Zea mays L.), Gibberella Ear Rot, Quantitative Trait Locus, Marker-Assisted Selection

Posted Date: January 15th, 2020

DOI: https://doi.org/10.21203/rs.2.20975/v1

License: (9) This work is licensed under a Creative Commons Attribution 4.0 International License.

Read Full License 


\section{Abstract}

Background: Gibberella ear rot (GER), a prevalent disease caused by Fusarium graminearum, can result in yield loss and mycotoxin contamination in maize. Despite that several QTLs related to GER resistance have been reported previously, few of them was identified in Chinese maize inbred lines. In this study, we employed a Chinese recombination inbred line (RIL) population comprising of 204 lines, developed from a cross involving a resistant parent DH4866 and a susceptible line T877. The population was phenotypically evaluated at three field trial locations under artificial inoculation with F. graminearum and genotyped with an Affymetrix microarray CGMB56K SNP Array to detect the quantitative trait loci (QTLs) for resistance to GER.

Results: Based on the genetic linkage map constructed using 1,868 bins as markers, a total of 15 QTLs were identified, and both DH4866 and T877 alleles at these QTLs contributed toward resistance. Of these QTLs, five were stably expressed across multiple locations, including three co-localized with previously reported genomic regions. The largest-effect QTL located on chromosome 4, qGER4.2, which accounted for $5.66 \sim 17.10 \%$ of the phenotypic variation, was detected at all locations. Based on the phenotypic values of the alleles corresponding to the five stable QTLs, a significant correlation $\left(r^{2}=0.45\right)$ between resistance to GER and the number of resistant alleles was observed.

Conclusions: QTL mapping was successfully employed to identify genetic loci conferring resistance to GER by a high-density genetic map constructed from two Chinese maize germplasms. The five stable QTLs identified, especially the large-effect QTL, qGER4.2, will be useful in maize breeding programs aimed at improving GER resistance.

\section{Background}

Maize ear rot, including Gibberella ear rot (GER) and Fusarium ear rot (FER), caused by Fusarium graminearum (Schwabe) and Fusarium verticillioedes (Nirenberg), respectively, is a devastating disease in most maize-growing regions in the world [1]. Fusarium infections on maize not only reduce yields, but contaminate kernels with carcinogenic mycotoxins, particularly deoxynivalenol, zearalenone and fumonisins, which have potential threats to animal and human health $[2,3,4,5]$. Due to the limited effect of agronomic practices and fungicides, breeding resistant varieties has been considered as a better alternative for improving maize production [6].

Quantitative genetic variations for resistance to GER usually have moderate to high heritability among different maize germplasms [2], suggesting that phenotypic selection for improved GER resistance should be effective. However, resistance to GER in maize is easily influenced by environment conditions and genotype $\times$ environment interaction $[2,7,8]$. To improve the resistance of inbred lines and hybrids, multienvironmental inoculation trials are necessary for accurate phenotype evaluation in conventional maize breeding programs [9]. However, this way is apparently labor-intensive and unsuitable for large segregating populations. 
Molecular marker-assisted selection (MAS) can potentially enhance the efficiency of breeding, and its effectiveness depends on functional genes and quantitative trait loci (QTLs) [10]. QTL mapping is a classical method for detecting QTLs for the traits of interest. Thus far, numerous studies have focused on efforts to detect QTLs conferring resistance to maize ear rot, mainly for FER, by mapping them on all chromosomes of maize using different biparental populations [2]. For instance, 22 QTLs for resistance to FER were detected using a multi-parent advanced generation inter-Cross population [11], while another study reported 15 QTLs for FER and 17 QTLs for FB1 content, respectively, using $F_{2: 3}$ population derived by $\mathrm{CO} 441 \times \mathrm{CO} 354$ [12]. By combining genome-wide association study and QTL mapping approaches, 15 QTLs for FER resistance were identified using a tropical population consisting of 940 elite inbred lines and four bi-parent populations [13]. Despite of the progress on QTL mapping for FER resistance, there is very limited report on GER QTLs. Recently, Han et al. (2018) [14] employed 130 dent and 114 flint lines from European maize breeding programs to dissect the genetic basis for resistance to GER by genotyping with the Illumina single-nucleotide polymorphism (SNP) chip MaizeSNP50. However, they could not detect any significant SNPs associated with resistance to GER, even though the prediction accuracy using SNP effect achieved 0.50 , confirming that the resistance to GER was controlled by numerous minor-effect loci. Hence, considering that GER resistance is a quantitative and additive complex trait attributed by multiple genes having minor effects, more QTLs for resistance to GER in different genetic backgrounds should be characterized and pyramided together via MAS to achieve a significant improvement in GER resistance.

To our knowledge, while previous reports used American and European germplasms for QTL mapping [7, $8,15,16,17,18]$, there are no published QTL studies on resistance to GER in Chinese maize germplasms. In the present study, a recombination inbred line (RIL) population with high recombination frequency, constructed from two Chinese elite inbred lines DH4866 and T877, was employed to detect the stably expressed QTLs conferring resistance to GER across multi-environments. Moreover, the combination effects of the stable QTLs were assessed.

\section{Results}

\section{Differences in resistance to GER between two parental lines}

To evaluate the differences in resistance to GER between the two parents, in vitro kernel assay and ear inoculation in field were performed. Kernel assay clearly showed that T877 kernel was more susceptible than DH4866, with more hyphae grown on the surface of T877 kernels than that of $\mathrm{DH} 4866$, at five days after inoculation (Fig. S2a). Moreover, the number of spores in the former was also significantly higher than that of the later (Fig. S2b). In line with the kernel assay, the disease severity of DH4866 (ranging from 2.20 to 2.80 ) was significantly lower than that of T877 (ranging from 5.08 to 6.33 ) across three locations in the field condition (Fig. 1).

\section{Phenotypic variance and heritability in RIL population}


Wide phenotypic variation among RIL population lines was observed from 1.59 to 6.93 in SY, from 1.18 to 6.83 in NT, from 1.00 to 7.00 in XX, and from 1.50 to 5.28 in BLUP, respectively (Table 1). The mean disease severity of RIL population were $3.55,3.53,3.28$ and 3.45 in SY, NT, XX and BLUP, respectively, and a significant positive correlation $(P<0.001)$ was observed between different locations (Fig. 2).

The disease severity at each location approximately fitted a normal distribution with little skewness and kurtosis (Table 1; Fig. 2), indicating that the resistance to GER was controlled by multiple genetic loci in this RIL population. The variances of genotype $\left(\sigma^{2}\right)$ and genotype $\times$ location $\left(\sigma_{g l}^{2}\right)$ were significant at $\mathrm{P}<$ 0.01 (Table 1), and the broad-sense heritability was moderate $(69.84 \%)$, suggesting that much of the phenotypic variation in this RIL population were genetically controlled.

\section{QTL mapping}

A total of 15 QTLs for resistance to GER was identified at an empirical LOD value of 3.00 after 1000 permutations through three locations and BLUP, which were distributed on 9 out of 10 chromosomes, excluding chromosome 5 (Table 2, Fig. 3). The phenotypic variation explained by a single QTL ranged from 1.02\% ( $q$ GER10.1 in NT) to 17.10\% ( $q$ GER4.2 in BLUP). Among them, only five QTLs ( $q$ GER3.3, qGER4.1, qGER4.2, qGER8 and qGER10.1) were identified in at least two locations, which were considered as stable QTLs, and the others were location-specific QTLs. Notably, qGER4.2, located on chromosome 4, was repeatedly detected in all the locations, accounted for $5.66 \sim 17.10 \%$ of the phenotypic variation, respectively. qGER4.2 was delimited to bin 4.09 , with approximately $34.7 \mathrm{cM}$ of genetic interval flanked by the markers PZE-104123745 and SYN22075. There are more than 1000 genes in this region, among which the candidate gene for $q G E R 4.2$ will be fine-mapped in the future.

To further understand the genetic architecture of resistance to GER, the additive $\times$ additive epistatic interactions for significant QTL in the RIL population were performed. No epistatic interactions were observed (data not shown), indicating that the genetic component of resistance to GER in this Chinese RIL population is mainly characterized by additive gene actions.

\section{Combined effect of QTL for resistance to GER}

To understand the combined effects of five stable resistant QTLs, we analyzed the number of resistant loci in each genotype. The number of resistant loci in each genotype ranged from 0 to 5 , and 22 haplotypes (each haplotype including at least three genotypes) were identified across five robust SNPs corresponding to the QTLs (Table 3). At group level, compared to genotypes without resistant locus, disease severity declined significantly in the genotype harboring one resistant locus, and the disease severity declined linearly with increasing numbers of resistant loci (Table 3). A significant negative correlation between the disease severity and the number of resistant loci was found in each haplotype ( $r^{2}$ $=0.45, P<0.001$ ) based on the linear regression analysis. 


\section{Discussion}

Construction of an appropriate mapping population is a prerequisite for QTL analysis. In this study, a maize RIL population derived from two Chinese maize elite inbred lines, DH4866 and T877 with high recombination frequency [19] was employed to identify the genetic loci conferring resistance to GER. There was a wide variation of resistance to GER in this RIL population, in which two parental lines showed large differences in resistance to GER in both field artificial inoculation and in vitro kernel assay (Fig. 1, Figure S2, Table 1), providing the reliable genetic resources for QTL mapping.

In this study, a total of 15 QTLs for resistance to GER were detected at three locations and BLUP (Table 2, Fig. 3). Nearly half of the resistant alleles of QTLs came from the susceptible parent T877. Similar findings from previous researches on resistant alleles from both susceptible and resistant parent corroborate our results $[7,8,17,18]$, which should be considered in breeding maize lines for resistance to GER.

Due to the specific expression of certain genes during the process of adaptation to different environments and experimental errors, the identified QTLs are inconsistent under different environments, which is a prominent characteristic of quantitative trait controlled by polygene [20,21]. The QTL, which is detected in multiple environments, is stable and might be a real locus that would be a good choice for MAS [22, 23]. Among 15 QTLs, five QTLs (qGER3.3, qGER4.1, qGER4.2, qGER8 and qGER10.1) were identified in at least two locations, and only one QTL (qGER4.2) was detected in all locations (Table 2). Although the LOD values of the remaining four QTLs were lower than the threshold, these QTLs still showed obvious LOD peaks when identified in different locations (Fig. 3). This phenomenon may be due to type-Il error arising from the use of a stringent threshold. Thus, we considered these five QTLs as stable QTLs.

Of the five stable QTLs, three (qGER3.3, qGER4.1 and qGER8) have been described previously (Xiang et al. 2010, Martin et al. 2011, Kebede et al. 2016), while the remaining two (qGER4.2 and qGER10.1) were putatively novel loci. qGER3.3 located in a meta-QTL region analyzed by Xiang et al. (2010) [24]. qGER4.1 and qGER8 were aligned with the genomic regions detected by Martin et al. (2011) [17] and Kebede et al. (2016) [8], respectively. Interestingly, the largest effect QTL qGER4.2 was overlapping with a QTL region for resistance to Aspergillus ear rot (AER) identified by Mideros et al. (2014) [25]. Given the large genomic region, it remains unclear whether it is a single gene or several closely linked resistant genes that have pleiotropic effects in chromosome bin 4.09. Thus, further fine mapping of the region should be worthwhile.

MAS has been successfully used in disease resistance improvement depending on the reliable resistant gene/QTLs in crop. For example, Konlasuk et al. (2015) [26] transferred a quantitative resistance gene for head smut (ZmWAK) into susceptible maize inbred lines assisted by MAS. The lines carrying ZmWAK showed enhanced disease resistance to head smut. Swathi et al. (2019) [27] pyramided two bacterial blight resistance genes (xa13 and Xa21) and one bacterial blast resistance gene (Pi54) to improve the resistance to bacterial blight and blast in rice via MAS. The pyramided lines with three genes exhibited 
higher level of resistance to bacterial blight and blast with better yield than the recurrent parent. In this study, we evaluated the combination effect of the five stable QTLs, showing that just one resistant QTL significantly improved the resistance to GER, while each additional resistant QTL had further additive

effect (Table 3). This result suggests that pyramiding of these resistant QTLs could enhance the resistance to GER level effectively in maize breeding.

In summary, QTL mapping was successfully employed to identify genetic loci for resistance to GER using Chinese maize germplasm. The QTLs identified here could further our understanding of the genetic mechanisms of GER, and provide potential applications in cloning the causal genes and breeding maize varieties resistance to GER.

\section{Methods}

\section{Plant materials and genotyping}

A RIL population consisting of 204 lines was developed from a cross between two Chinese maize inbred lines DH4866 (resistant) and T877 (susceptible). The resistant line DH4866 was derived from a cross between the two Chinese elite inbred lines 7922 and Ye478. The susceptible line T877 was developed from a cross between an American hybrid 78599 and a Chinese elite inbred line E28 [28]. This population was generated, identified, maintained, and provided by Jiangsu Yanjiang Institute of Agricultural Sciences, Nantong, China, and was not deposited elsewhere.

The RIL population and two parental inbred lines were genotyped with an Affymetrix microarray CGMB56K SNP Array, which contains 56,000 maize SNPs, made by China Golden Marker (Beijing) Biotech Co., Beijing, China. After quality control, 9,780 high-quality polymorphic SNPs were used to construct linkage map. The genetic linkage map contained 1,868 bin markers and spanned a total length of $3,081.8 \mathrm{cM}$, with a mean interval length of $1.65 \mathrm{cM}$. Detailed information on construction of the bin map has been reported previously [19].

\section{Field trials and phenotyping}

The RIL population and its parents were planted at three locations of China in 2019: Sanya, Hainan Province $\left(\mathrm{SY}, 108^{\circ} \mathrm{E}, 18^{\circ} \mathrm{N}\right)$; Nantong, Jiangsu Province $\left(\mathrm{NT}, 120^{\circ} \mathrm{E}, 31^{\circ} \mathrm{N}\right)$ and Xinxiang, Henan Province $\left(X X, 113^{\circ} \mathrm{E}, 35^{\circ} \mathrm{N}\right)$. Each genotype was grown in single rows with $3.0 \mathrm{~m}$ in length and spaced $0.6 \mathrm{~m}$ between rows with a planting density of 65,000 plants $/ \mathrm{hm}^{2}$, following a randomized complete block design with two replications per location. The field management followed common agricultural practice at the three locations.

Artificial inoculation with an aggressive isolate of F. graminearum (strain F0609) was conducted. The fungal inoculum was prepared according to Sun et al. (2018) [29]. Briefly, the strain was cultured on potato dextrose agar (PDA) medium for about two weeks, followed by culturing several agar plugs with 
fully grown mycelium in sterilized mung bean soup at $200 \mathrm{rpm}, 28{ }^{\circ} \mathrm{C}$ for $2 \sim 3 \mathrm{~d}$. The spore suspension was filtered, counted and adjusted to a concentration of $1 \times 10^{6}$ spores $/ \mathrm{ml}$ supplemented with $0.001 \%$ surfactant Tween-20. For field inoculation, approximately $10 \mathrm{~d}$ after silk emergency, the primary ear of each plant per plot was pierced at the base, middle and top of a husk. 1-2 kernels were stabbed by a $10 \mathrm{~cm}$ needle, but not reaching the cob, and then three wounds were injected with $200 \mathrm{ul}$ of spore suspension. At the physiological maturity stage, inoculated ears were harvested, and the disease severity of each ear was scored using a rating scale from 1 to $7(1=0 \%, 2=1-3 \%, 3=4-10 \%, 4=11 \%$ to $25 \%, 5=$ $26-50 \%, 6=51-75 \%$, and $7=76-100 \%$ kernels showing visible disease symptoms) (Figure S1) [30]. The average of two replicates in each location was used for subsequent analysis.

The kernel assay was conducted according to the protocol for F. verticilloiedes described by Gao et al. (2007) [31]. Three replicates were included for each line, and at least three independent experiments were conducted with consistent results obtained.

\section{Phenotypic data analysis}

The phenotypic statistical analysis was performed using R version 3.6.0 software (https://www.rproject.org/). The correlation analysis for each location was conducted by the chart.Correlation function of the PerformanceAnalytics package [32]. Analysis of variance of disease severity was performed using the Imer function of the Ime4 package [33] based on the following model: $y_{i j}=\mu+g_{i}+e_{j}+g_{i j}+\varepsilon_{i j}$, where $y_{i j}$ is the trait measured, $\mu$ is the grand mean for all locations, $g_{i}$ is the genotypic effect for the ith genotype, $e_{j}$ is the locational effect for the $\mathrm{jth}$ location, $\mathrm{ge}_{\mathrm{ij}}$ is the genotype $\times$ location interaction effect,

and $\varepsilon_{\mathrm{ij}}$ is the residual error. The broad-sense heritability $\left(\mathrm{H}^{2}\right)$ was estimated following Knapp et al. (1985) [34]: $H^{2}(\%)=\sigma_{g}^{2} /\left(\sigma_{g}^{2}+\sigma_{g e}^{2} / n+\sigma_{e}^{2} / n r\right)$, where $\sigma_{g}^{2}$ is the genotypic variance, $\sigma^{2}$ ge is the interaction of the genotype with the location, $\sigma^{2}$ is the error variance, $n$ is the number of locations, and $r$ is the number of replications. The best linear unbiased prediction (BLUP) values of each line was estimated to less environmental error.

\section{QTL mapping}

QTL mapping was performed using composite interval mapping (CIM) [35] in Windows QTL Cartographer 2.5 [36]. Model 6 of the Zmapqtl module was selected to detect QTLs and their effects with scanning every $0.5 \mathrm{cM}$ at a window size of $10 \mathrm{cM}$. Forward-backward stepwise regression with five controlling markers was used to control the background from flanking markers. After 1000 permutations, the threshold logarithm of the odds (LOD) value was determined at a significance level of $P<0.05$. The confidence interval of QTL positions was estimated with the 1.5-LOD support interval method. Multiple interval mapping (MIM) in Windows QTL Cartographer 2.5 was performed to estimate the interactions of identified QTLs with the Bayesian Information Criteria as the criteria [37]. 


\section{Abbreviations}

GER:Gibberella ear rot; FER:Fusarium ear rot; MAS:Marker-assisted selection; QTL:Quantitative trait locus; SNP:Single nucleotide polymorphism; RIL:Recombinant inbred line; LOD:Logarithm of the odds; BLUP:Best linear unbiased prediction; $\mathrm{R}^{2}$ :Percentage of phenotypic variance explained; CIM:Composite interval mapping; MIM:Multiple interval mapping

\section{Declarations}

Ethics approval and consent to participate

Not applicable.

\section{Consent for publication}

Not applicable.

\section{Availability of data and materials}

The datasets used and/or analyzed in the current study are available from the corresponding author on request.

\section{Completing interest}

The authors declare that they have no conflict of interest.

\section{Funding}

This work is supported financially by the grants from The National Key Research and Development Program of China (No. 2016YFD0101002), National Science Foundation of China (No. 31671702, No. 31471508), Technology Foundation for Selected Overseas Chinese Scholar, Ministry of Personnel of China (No. G0101500090), and that from Jiangsu Collaborative Innovation Center for Modern Crop Production (JCIC-MCP) and Innovation Team Program for Jiangsu Universities (2014) to X.G.. The funding providers were not involved in the design of the study, data collection, interpretation of data, or in writing the manuscript.

\section{Authors' contributions}

GZ analyzed data and wrote the manuscript; GZ, SL, LM, FW, YS, XR, YC, QW and XG carried out the field experiments; XG designed the study and wrote the manuscript. All authors have read and approved the final version of the manuscript.

\section{Acknowledgements}

We greatly appreciate the helpful comments on the manuscript from anonymous reviewers. 


\section{Authors' information}

${ }^{1}$ State Key Laboratory for Crop Genetics and Germplasm Enhancement, Nanjing Agricultural University, Nanjing 210095, P. R. China; ${ }^{2}$ Jiangsu Yanjiang Institute of Agricultural Sciences, Nantong 226541, P. R. China; ${ }^{3}$ Jiangsu Collaborative Innovation Center for Modern Crop Production, Nanjing Agricultural University, Nanjing 210095, P. R. China; ${ }^{4}$ College of Agriculture, Nanjing Agricultural University, Nanjing 210095, P. R. China

\section{References}

1. Mesterhazy A, Lemmens M, Reid LM. Breeding for resistance to ear rots caused by Fusarium in maize-a review. Plant Breed. 2012; 131: 1-19.

2. Gaikpa DS and Miedaner T. Genomics-assisted breeding for ear rot resistances and reduced mycotoxins contamination in maize: methods, advances and prospects. Theor Appl Genet. 2019; 132: 2721-2739.

3. Pinton P, Oswald I. Effect of deoxynivalenol and other type B trichothecenes on the intestine: a review. Toxins. 2014; 6: 1615-1643.

4. Vigier BL, Reid LM, Dwyer LM, Stewart DW, Sinha RC, Arnason JT, Butler G. Maize resistance to Gibberella ear rot: Symptoms, deoxynivalenol, and yield. Can J Plant Pathol. 2001; 23: 99-105.

5. Zhou M, Yang LJ, Shao MH, Wang YX, Yang WR, Huang LB, Zhou XM, Jiang S Z, Yang Z B. Effects of zearalenone exposure on the TGF- $\beta 1 /$ Smad3 signaling pathway and the expression of proliferation or apoptosis related genes of post-weaning gilts. Toxins. 2018; 10: 49.

6. Mounkvold GP. Cultural and genetic approaches to managing mycotoxins in maize. Annu Rev Phytopathol. 2003; 41: 99-116.

7. Ali ML, Taylor JH, Jie L, Sun G, William M, Kasha KJ, Reid LM, Pauls KP. Molecular mapping of QTLs for resistance to Gibberella ear rot, in corn, caused by Fusarium graminearum. Genome. 2005; 48: 521-533.

8. Kebede AZ, Woldemariam T, Reid LM, Harris LJ. Quantitative trait loci mapping for Gibberella ear rot resistance and associated agronomic traits using genotyping-by-sequencing in maize. Theor Appl Genet. 2016; 129: 17-29.

9. Loffler M, Kessel B, Ouzunova M, Miedaner T. Population parameters for resistance to Fusarium graminearum and Fusarium verticillioides ear rot among large sets of early, mid-late and late maturing European maize (Zea mays) inbred lines. Theor Appl Genet. 2010; 120: 1053-1062.

10. Collard BC and Mackill DJ. Marker-assisted selection: an approach for precision plant breeding in the twenty-first century. Philos Trans R Soc Lond B BioL Sci. 2008; 363: 557-572.

11. Butrón A, Santiago R, Cao A, Samayoa LF Malvar RA. QTLs for resistance to Fusarium ear rot in a multi-parent advanced generation inter-cross (MAGIC) of maize population. Plant Dis. 2019; https://doi.org/10.1094/PDIS-09-18-1669-RE. 
12. Maschietto V, Colombi C, Pirona R, Pea G, Strozzi F, Marocco, Rossini L, Lanubile A. QTL mapping and candidate genes for resistance to Fusariumear rot and fumonisin contamination in maize. BMC Plant Biol. 2017; 17: 20.

13. Chen JF, Shrestha R, Ding JQ, Zheng HJ, Mu CH, Wu JY Mahuku G. Genome-wide association study and QTL mapping reveal genomic Loci associated with Fusarium ear rot resistance in tropical maize germplasm. G3-Genes Genomes Genetics. 2016; 6(12): 3803-3815.

14. Han S, Miedaner T, Utz HF, Schipprack W, Schrag TA, Melchinger AE. Genomic prediction and GWAS of Gibberella ear rot resistance traits in dent and flint lines of a public maize breeding program. Euphytica. 2018; 214: 6.

15. Han S, Utz HF, Liu WX, Schrag TA, Stange M, Wurschum T, Miedaner T, Bauer E, Schon CC, Melchinger AE. Choice of models for QTL mapping with multiple families and design of the training set for prediction of Fusarium resistance traits in maize. Theor Appl Genet. 2016; 129: 431-444.

16. Giomi GM, Kreff ED, Iglesias J Fauguel CM, Fernandez M, Ooviedo MS, Presello DA. Quantitative trait loci for Fusarium and Gibberella ear rot resistance in Argentinian maize germplasm. Euphytica. 2016; 211: 287.

17. Martin M, Miedaner T, Dhillon BS, Ufermann U, Kessel B, Ouzunova M, Schipprack W, Melchinger AE. Colocalization of QTL for Gibberella ear rot resistance and low mycotoxin contamination in early European maize. Crop Sci. 2011; 51: 1935-1945.

18. Martin M, Miedaner T, Schwegler DD, Kessel B, Ouzunova M, Dhillon BS, Schipprack W, Utz HF, Melchinger AE. Comparative quantitative trait loci mapping for Gibberella ear rot resistance and reduced deoxynivalenol contamination across connected maize populations. Crop Sci. 2012; 52: 3243.

19. Li PC, Zhang YY, Yin SY, Zhu PF, Pan T, Xu Y, Wang JY, Hao DR, Fang HM, Xu CW, Yang ZF. QTL-byenvironment interaction in the response of maize root and shoot traits to different water regimes. Front Plant Sci. 2018; 9: 229.

20. Li ZK, Yu SB, Lafitte HR, Huang N, Courtois B, Hittalmani S, Vijayakumar CHM, Liu GF, Wang GC, Shashidhar HE, Zhuang JY, Zheng KL, Singh VP, Sidhu JS, Srivantaneeyakul S, Khush GS. QTL × environment interactions in rice. I. Heading data and plant height. Theor Appl Genet. 2003; 108: 141153.

21. Xu YB Molecular plant breeding. CAB International, Wallingford. 2010.

22. Malosetti M, Ribaut JM, Vargas M, Crossa J, Eeuwijk FA. A multi-trait multi-environment QTL mixed model with an application to drought and nitrogen stress traits in maize (Zea mays). Euphytica. 2008; 161: 241-257.

23. Messmer R, Fracheboud $Y$, Banziger M, Vargas M, Stamp P, Ribaut JM. Drought stress and tropical maize: QTL-by-environment interactions and stability of QTLs across environments for yield components and secondary traits. Theor Appl Genet. 2009; 119: 913-930.

24. Xiang K, Zhang ZM, Reid LM, Zhu XY, Yuan GS, Pan GT. A meta-analysis of QTL associated with ear rot resistance in maize. Maydica. 2010; 55: 281-290. 
25. Mideros SX, Warburton ML, Jamann TM, Windham GL, Willians WP, Nelson RJ. Quantitative trait loci influencing mycotoxin contamination of maize: analysis by linkage mapping, characterization of near-isogenic lines, and meta-analysis. Crop Sci. 2014; 54: 127-142.

26. Konlasuk S, Xing YX, Zhang N, Zuo WL, Zhang BQ, Yan GQ, Xu ML. ZmWAK, a quantitative resistance gene to head smut in maize, improves yield performance by reducing the endophytic pathogen Sporisorium reiliana. Mol Breed. 2015; 35: 174.

27. Swathi G, Durga Rani, Md J, Madhav MS, Vanisree S, Anuradha C, Kumar NR, Kumar NAR, Kumar KA, Bhogadhi SC, Ramprasad E, Sravanthi P, Raju SK, Bhuvaneswari V, Rajan CPD, Jagadeeswar R. Marker-assisted introgression of the major bacterial blight resistance genes, Xa21 and xa13, and blast resistance gene, Pi54, into the popular rice variety, JGL1798. Mol Breed. 2019; 39: 58.

28. Zhou GF, Hao DR, Xue L, Chen GQ, Lu HH, Zhang ZL, Shi ML, Huang XL, Mao YX. Genome-wide association study of kernel moisture content at harvest stage in maize. Breed Sci. 2018; 68: 622-628.

29. Sun YL, Ruan XS, Ma L, Wang F, Gao XQ. Rapid screening and evaluation of maize seedling resistance to stalk rot caused by Fusarium. Bio-Protocol. 2018; 8(10): e2859.

30. Reid LM, Mather DE, Bolton AT, Hamilton RI. Evidence for a gene for silk resistance to Fusarium graminearum ear rot of maize. J Hered. 1994; 85:118-121.

31. Gao XQ, Shim W-B, Gobel C, Kunze S, Fuessner I, Meeley R, Balint-Kurti P, Kolomiets MV. Disruption of a maize 9-lipoxygenase results in increased resistance to fungal pathogens and reduced levels of contamination with mycotoxin fumonisin. Mol Plant-Microbe Interact. 2007; 20: 922-933.

32. Peterson BG, Carl P, Boudt K, Bennett R, Ulrich J, Zivot E, Lestel M, Balkissoon K, Wuertz D. PerformanceAnalytics: Econometric tools for performance and risk analysis. $\mathrm{R}$ package version 1.4.3541. 2014.

33. Bates D, Maechler M, Bolker B, Walker S. Fitting linear mixed-effects models using Ime4. Journal of Statistical Software. 2015; 67: 1-48.

34. Knapp SJ, Stroup WW, Ross WM. Exact confidence intervals for heritability on a progeny mean basis. Crop Sci. 1985; 25(1): 192-194.

35. Zeng ZB. Precision mapping of quantitative trait loci. Genetics. 1994; 136(4): 1457-1468.

36. Wang S, Basten CJ, Zeng ZB. Windows QTL cartographer 2.5. Department of Statistics, North Carolina State University, Raleigh. 2011.

37. Kao CH, Zeng ZB, Teasdale RD. Multiple interval mapping for quantitative trait loci. Genetics. 1999; 152(3): 1203-1216.

\section{Tables}


Table 1 Phenotypic performance, variance component and broad-sense heritability of resistance to GER in RIL population

$\begin{array}{llllllll}\text { Location } & \text { Mean } \pm \text { SD } & \text { Range } & \text { Skewness } & \text { Kurtosis } & \sigma^{2}{ }_{g} & \sigma^{2}{ }_{g l} & H^{2}(\%) \\ \text { SY } & 3.55 \pm 0.93 & 1.59-6.93 & 0.51 & 0.60 & & & \\ \text { NT } & 3.53 \pm 1.15 & 1.18-6.83 & -0.10 & 0.39 & & & \\ \text { XX } & 3.28 \pm 1.03 & 1.00-7.00 & 0.76 & 0.38 & & & \\ \text { BLUP } & 3.45 \pm 0.56 & 1.50-5.28 & 0.86 & 0.28 & 0.44^{* *} & 0.16^{* *} & 69.84\end{array}$

SY: Sanya; NT: Nantong; XX: Xinxiang; BLUP: best linear unbiased prediction; SD: standard deviation; $\sigma^{2}$ : the genotypic variance; $\sigma^{2}{ }_{g}$ : the interactions of genotype with location; $H^{2}(\%)$ : broad-sense heritability; ${ }^{* *}$ Significant at $P<0.01$. 
Table 2 QTLs were detected for resistance to GER in RIL population

\begin{tabular}{|c|c|c|c|c|c|c|c|c|}
\hline QTL & Loc. & Bin & Marker interval & $\begin{array}{l}\text { Genetic } \\
\text { interval } \\
\text { (cM) }\end{array}$ & $\begin{array}{l}\text { Physical } \\
\text { position } \\
(\mathrm{Mb})\end{array}$ & LOD & $\mathrm{R}^{2}(\%)$ & Add. \\
\hline$q G E R 1$ & NT & 1.04 & $\begin{array}{l}\text { SYN10803- } \\
\text { SYN2042 }\end{array}$ & $\begin{array}{l}122.30- \\
146.21\end{array}$ & $\begin{array}{l}51.76- \\
70.86\end{array}$ & 4.16 & 6.15 & -0.26 \\
\hline qGER2 & $x X$ & 2.10 & $\begin{array}{l}\text { SYN20399- } \\
\text { SYN14631 }\end{array}$ & $\begin{array}{l}270.88- \\
279.05\end{array}$ & $\begin{array}{l}239.07- \\
239.77\end{array}$ & 4.06 & 1.58 & 0.08 \\
\hline qGER3.1 & $x X$ & 3.02 & $\begin{array}{l}\text { PZE- } \\
103012466- \\
\text { PZE- } \\
103017733\end{array}$ & $\begin{array}{l}41.8- \\
70.39\end{array}$ & $5.80-9.58$ & 3.84 & 7.25 & -0.31 \\
\hline qGER3.2 & SY & 3.05 & $\begin{array}{l}\text { PZE- } \\
103078702- \\
\text { PZE- } \\
103083874\end{array}$ & $\begin{array}{l}154.77- \\
161.35\end{array}$ & $\begin{array}{l}130.57- \\
139.49\end{array}$ & 3.20 & 1.05 & -0.03 \\
\hline
\end{tabular}

$\begin{array}{rllllllll}\text { qGER3.3 NT } 3.06 \quad \text { PZE- } & 208.96- & 179.37- & 3.00 & 3.81 & 0.25 \\ & & & 1031148157- & 223.41 & 184.96 & & & \\ & \text { PZE- } & & \\ & & & & \end{array}$

\begin{tabular}{|c|c|c|c|c|c|c|c|c|}
\hline & BLUP & 3.06 & $\begin{array}{l}\text { PZE- } \\
\text { 1031148157- } \\
\text { PZE- } \\
103124740\end{array}$ & $\begin{array}{l}208.96- \\
223.41\end{array}$ & $\begin{array}{l}179.37- \\
184.96\end{array}$ & 4.06 & 8.12 & 0.13 \\
\hline qGER3.4 & SY & 3.09 & $\begin{array}{l}\text { PZE- } \\
103178060- \\
\text { SYN32844 }\end{array}$ & $\begin{array}{l}295.11- \\
298.61\end{array}$ & $\begin{array}{l}227.51- \\
228.02\end{array}$ & 3.23 & 1.78 & 0.11 \\
\hline \multirow[t]{3}{*}{ qGER4.1 } & SY & 4.05 & $\begin{array}{l}\text { PZE- } \\
104046073- \\
\text { PZE- } \\
104046899\end{array}$ & $\begin{array}{l}124.69- \\
132.89\end{array}$ & $\begin{array}{l}\text { 72.07- } \\
73.55\end{array}$ & 3.76 & 2.05 & 0.03 \\
\hline & NT & 4.05 & $\begin{array}{l}\text { PZE- } \\
104046073- \\
\text { SYN1338 }\end{array}$ & $\begin{array}{l}124.69- \\
133.51\end{array}$ & $\begin{array}{l}\text { 72.07- } \\
75.57\end{array}$ & 4.66 & 4.22 & 0.14 \\
\hline & BLUP & 4.05 & $\begin{array}{l}\text { PZE- } \\
104021283- \\
\text { SYN1338 }\end{array}$ & $\begin{array}{l}101.37- \\
133.51\end{array}$ & $\begin{array}{l}24.28- \\
75.54\end{array}$ & 4.70 & 8.24 & 0.11 \\
\hline \multirow[t]{3}{*}{ qGER4.2 } & SY & 4.09 & $\begin{array}{l}\text { PZE- } \\
104123745- \\
\text { SYN22075 }\end{array}$ & $\begin{array}{l}251.87- \\
286.56\end{array}$ & $\begin{array}{l}205.27- \\
239.38\end{array}$ & 8.69 & 10.12 & -0.31 \\
\hline & NT & 4.09 & $\begin{array}{l}\text { PZE- } \\
104123745- \\
\text { SYN22075 }\end{array}$ & $\begin{array}{l}251.87- \\
286.56\end{array}$ & $\begin{array}{l}205.27- \\
239.38\end{array}$ & 4.14 & 5.66 & -0.34 \\
\hline & $x X$ & 4.09 & $\begin{array}{l}\text { PZE- } \\
104123745-\end{array}$ & $\begin{array}{l}251.87- \\
286.56\end{array}$ & $\begin{array}{l}205.27- \\
239.38\end{array}$ & 4.55 & 6.97 & -0.34 \\
\hline
\end{tabular}


SYN22075

\begin{tabular}{|c|c|c|c|c|c|c|c|c|}
\hline & BLUP & 4.09 & $\begin{array}{l}\text { PZE- } \\
104123745- \\
\text { SYN22075 }\end{array}$ & $\begin{array}{l}251.87- \\
286.56\end{array}$ & $\begin{array}{l}205.27- \\
239.38\end{array}$ & 6.05 & 17.10 & -0.47 \\
\hline qGER6 & SY & 6.01 & $\begin{array}{l}\text { PZE- } \\
106007419- \\
\text { PZE- } \\
106008388\end{array}$ & $\begin{array}{l}28.42- \\
28.91\end{array}$ & $\begin{array}{l}19.82- \\
25.58\end{array}$ & 3.41 & 2.43 & -0.17 \\
\hline qGER7 & NT & 7.03 & $\begin{array}{l}\text { SYN22175-PZE- } \\
107091680\end{array}$ & $\begin{array}{l}162.71- \\
170.86\end{array}$ & $\begin{array}{l}145.87- \\
151.81\end{array}$ & 3.32 & 2.86 & 0.18 \\
\hline \multirow[t]{3}{*}{ qGER8 } & SY & 8.05 & $\begin{array}{l}\text { PZE- } \\
108081311- \\
\text { PZE- } \\
108091439\end{array}$ & $\begin{array}{l}172.23- \\
194.04\end{array}$ & $\begin{array}{l}142.29- \\
152.92\end{array}$ & 3.00 & 5.21 & -0.21 \\
\hline & NT & 8.05 & $\begin{array}{l}\text { PZE- } \\
108070556- \\
\text { PZE- } \\
108090521\end{array}$ & $\begin{array}{l}159.36- \\
184.43\end{array}$ & $\begin{array}{l}126.91- \\
152.11\end{array}$ & 4.21 & 7.23 & -0.36 \\
\hline & BLUP & 8.05 & $\begin{array}{l}\text { PZE- } \\
108081311- \\
\text { PZE- } \\
108091439\end{array}$ & $\begin{array}{l}172.23- \\
194.04\end{array}$ & $\begin{array}{l}142.29- \\
152.92\end{array}$ & 5.11 & 11.70 & -0.15 \\
\hline qGER9.1 & SY & 9.01 & $\begin{array}{l}\text { PZE- } \\
109005409- \\
\text { PZE- } \\
109006644\end{array}$ & $\begin{array}{l}12.66- \\
16.22\end{array}$ & $5.60-7.17$ & 3.04 & 1.37 & -0.08 \\
\hline qGER9.2 & NT & 9.06 & $\begin{array}{l}\text { PZE- } \\
109076582- \\
\text { PZE- } \\
109089936\end{array}$ & $\begin{array}{l}124.87- \\
146.66\end{array}$ & $\begin{array}{l}125.82- \\
140.32\end{array}$ & 4.00 & 4.01 & -0.24 \\
\hline \multirow[t]{2}{*}{ qGER10.1 } & NT & 10.06 & $\begin{array}{l}\text { PZE- } \\
110080741- \\
\text { PZE- } \\
110085540\end{array}$ & $\begin{array}{l}139.61- \\
149.56\end{array}$ & $\begin{array}{l}135.96- \\
138.35\end{array}$ & 3.15 & 1.02 & 0.07 \\
\hline & BLUP & 10.06 & $\begin{array}{l}\text { PZE- } \\
110080741- \\
\text { PZE- } \\
110085540\end{array}$ & $\begin{array}{l}139.61- \\
149.56\end{array}$ & $\begin{array}{l}135.96- \\
138.35\end{array}$ & 3.04 & 2.78 & 0.04 \\
\hline qGER10.2 & NT & 10.07 & $\begin{array}{l}\text { PZE- } \\
110105429- \\
\text { PZE- } \\
110109364\end{array}$ & $\begin{array}{l}198.11- \\
211.71\end{array}$ & $\begin{array}{l}147.55- \\
149.24\end{array}$ & 3.08 & 1.05 & 0.03 \\
\hline
\end{tabular}

Loc.: location; SY: Sanya; NT: Nantong; XX: Xinxiang; BLUP: best linear unbiased prediction; $\mathrm{R}^{2}$ : percentage of phenotypic variance explained; Add. : additive effect; Add. of QTL with negative value 
indicates the contribution of resistant parent, $\mathrm{DH} 4866$, while positive value indicates the contribution of susceptible parent, T877; Physical position indicates the position of B73 RefGen_v4.

\section{Supplementary Figure Captions}

Fig. S1 Different disease resistance levels of GER in the field.

Fig. S2 The phenotype of two parental lines DH4866 and T877 examined by in vitro kernel assay.

a Photo for kernels of DH4866 and T877 at 5 days post inoculation.

b Comparisons of the number of spores between DH4866 and T877 in three replicates. ${ }^{* \star \star}$ indicates the significance level at $P<0.001$.

\section{Figures}
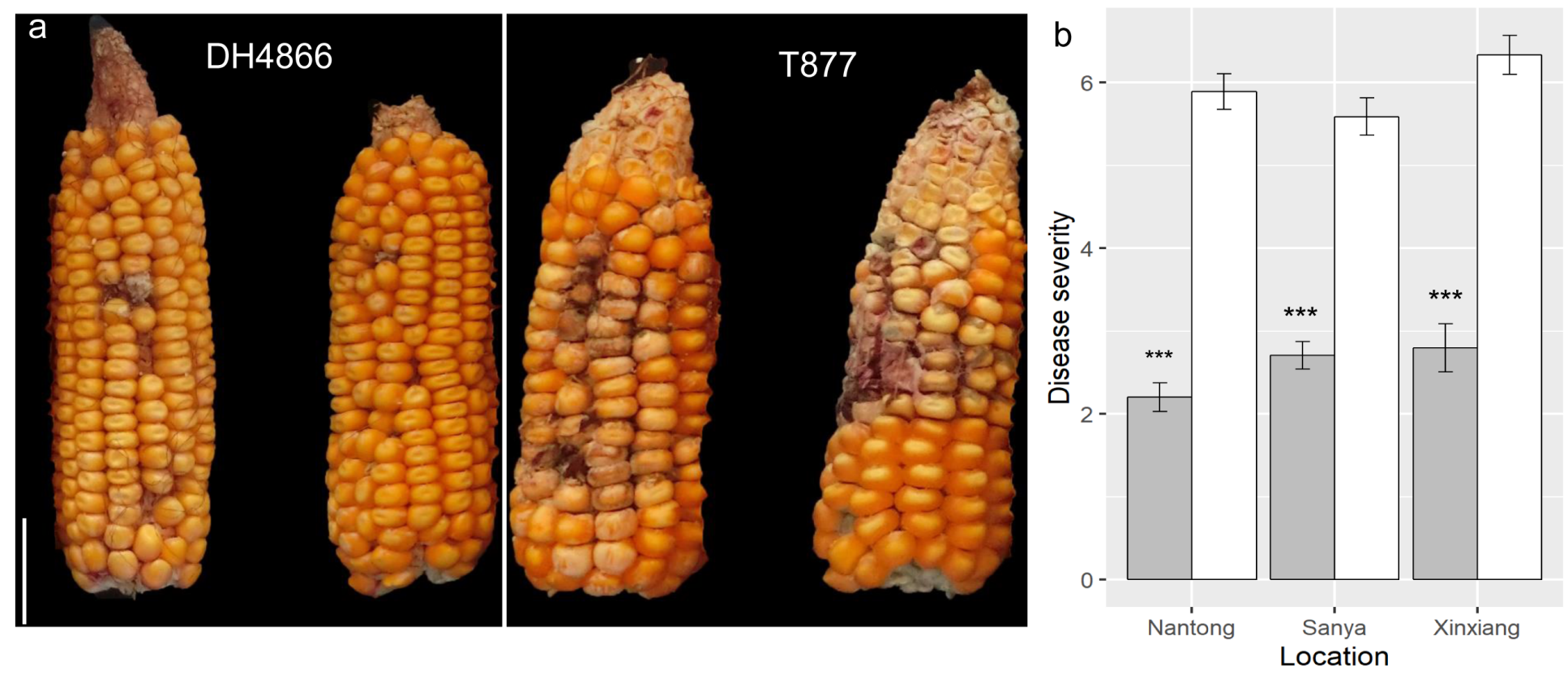

\section{Figure 1}

The resistance of two parental lines DH4866 and T877 to GER. The photo for ear rot phenotype of two parents DH4866 and T877 after inoculation in the field, Bar: $2 \mathrm{~cm}$. b Comparison of disease severity between DH4866 and T877 at three locations, the number of individuals was 20/18, 17/17 and 10/9 for DH4866/T877 at Nantong, Sanya and Xinxiang, respectively. *** indicates the significance level at $\mathrm{P}<$ 0.001 . 
Table 3 Haplotypes identified using five stable QTLs and their phenotypic effects

\begin{tabular}{|c|c|c|c|c|c|c|c|c|}
\hline Haplotype & qGER3.3 & qGER4.1 & qGER4.2 & qGER8 & qGER10.1 & No. & Sum & $\begin{array}{l}\text { Average of } \\
\text { disease } \\
\text { severity }\end{array}$ \\
\hline 1 & + & + & + & + & + & 6 & 5 & $2.94 \pm 0.26^{a}$ \\
\hline 2 & + & + & - & + & + & 9 & 4 & $3.10 \pm 0.27^{a}$ \\
\hline 3 & + & + & + & - & + & 10 & & \\
\hline 4 & + & + & + & + & - & 4 & & \\
\hline 5 & - & + & + & + & + & 4 & & \\
\hline 6 & + & + & - & - & + & 9 & 3 & $3.37 \pm 0.20^{b}$ \\
\hline 7 & + & + & - & + & - & 9 & & \\
\hline 8 & + & + & + & - & - & 8 & & \\
\hline 9 & - & + & - & + & + & 8 & & \\
\hline 10 & - & + & + & - & + & 10 & & \\
\hline 11 & + & + & - & - & - & 17 & 2 & $3.45 \pm 0.21^{b}$ \\
\hline 12 & + & - & - & - & + & 6 & & \\
\hline 13 & + & - & - & + & - & 7 & & \\
\hline 14 & + & - & + & - & - & 4 & & \\
\hline 15 & - & + & - & - & + & 9 & & \\
\hline 16 & - & + & + & - & - & 11 & & \\
\hline 17 & - & - & + & - & + & 5 & & \\
\hline 18 & - & - & + & + & - & 7 & & \\
\hline 19 & - & + & - & - & - & 10 & 1 & $3.73 \pm 0.30^{c}$ \\
\hline 20 & - & - & - & - & + & 3 & & \\
\hline 21 & - & - & + & - & - & 5 & & \\
\hline 22 & - & - & - & - & - & 9 & 0 & $4.22 \pm 0.31^{d}$ \\
\hline
\end{tabular}

No.: the number of lines; Sum: the sum of resistant QTLs; +: the resistant QTL is existent; -: the resistant QTL is non-existent; Average of disease severity was calculated using BLUP values; Different letters indicate significant difference at $P<0.05$ estimated by LSD test. 


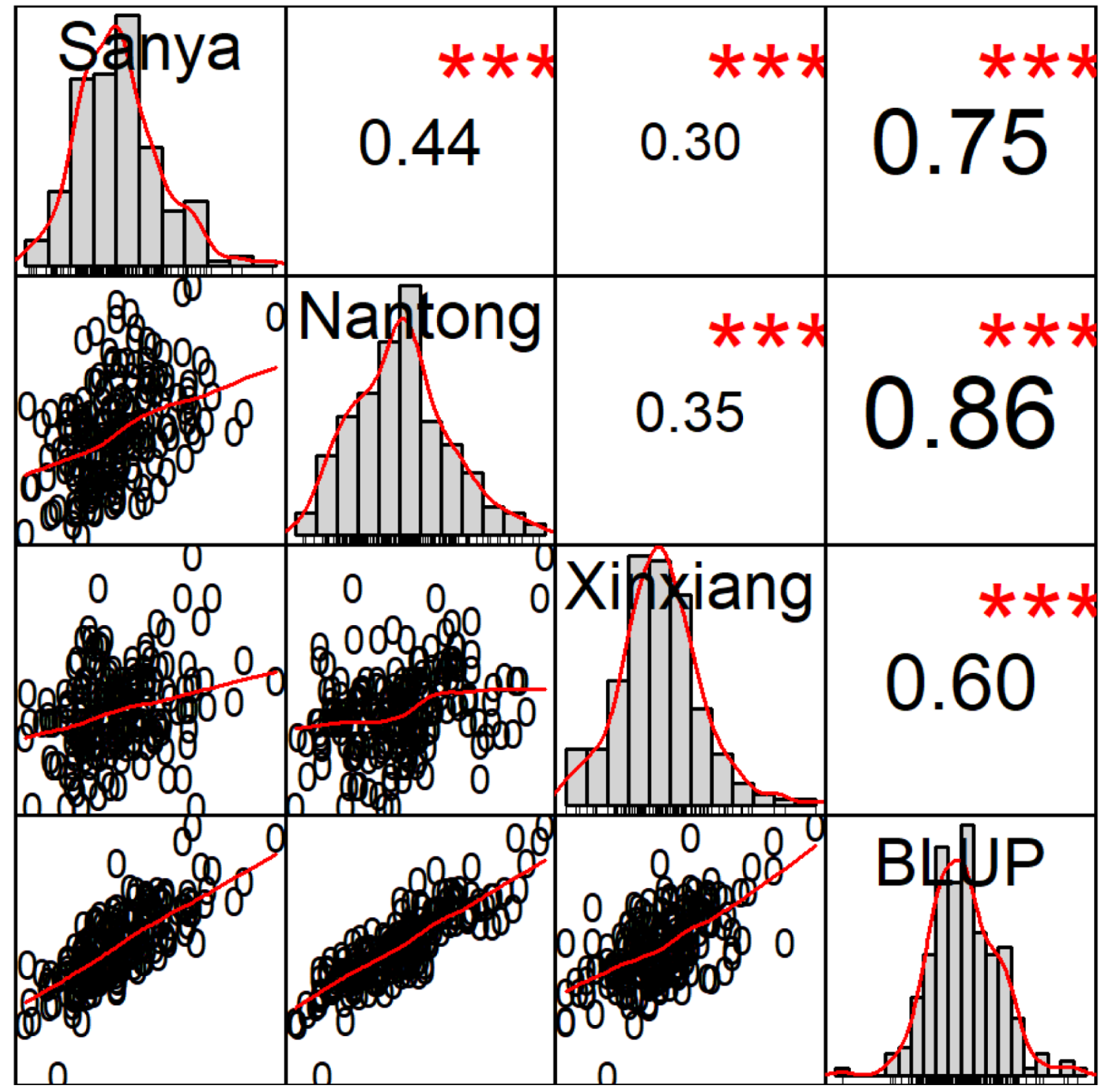

Figure 2

Correlation and frequency distribution of resistance to GER at three locations and BLUP. The upper panel is correlation coefficients, and the lower panel is scatter plots. The diagonal represents the frequency distribution of the trait. ${ }^{\star * \star}$ indicates the significance level at $\mathrm{P}<0.001$. 

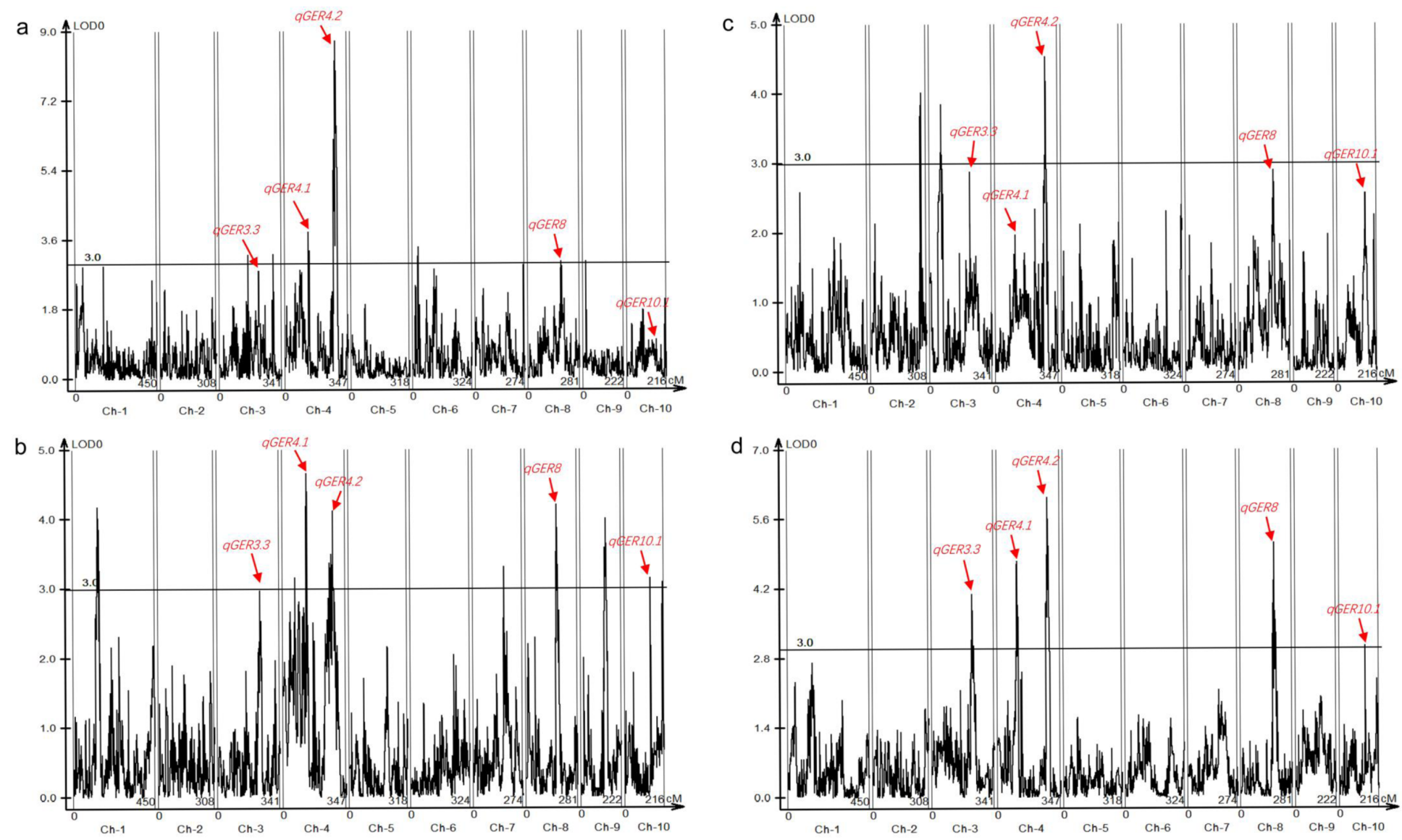

Figure 3

The distribution of QTLs for resistance to GER across entire genome in the RIL population. a-d The results of Sanya (SY), Nantong (NT), Xinxiang (XX) and best linear unbiased prediction (BLUP), respectively

\section{Supplementary Files}

This is a list of supplementary files associated with this preprint. Click to download.

- Fig.S2.tif

- Fig.S1.tif 